\title{
Fabrication of Highly Microstructure Controlled Ceramics by Novel Colloidal Processing
}

\author{
Yoshio SAKKA \\ Nano Ceramics Center, National Institute for Materials Science, 1-2-1, Sengen, Tsukuba-shi, Ibaraki 305-0047
}

\author{
新規コロイドプロセスによる高次構造制御セラミックスの創製 \\ 目 義雄 \\ 物質・材料研究機構ナノセラミックスセンター, 305-0047 つくば市千現 1-2-1
}

\begin{abstract}
Highly microstructure controlled ceramics are required for improving their properties. Colloidal processing using fine particles provides this required control mechanism through a well-dispersed suspension or heterocoagulate suspension. As a merit of colloidal processing, the preparation of superplastic zirconia is demonstrated using sub-micronsized powders. Highly microstructure controlled ceramics fabricated by a novel colloidal processing were demonstrated as follows: (i) dense nano-sized zirconia without pressure sintering, (ii) porous ceramics with controlled pore size by hetero-coagulated suspension of ceramics and polymer, and (iii) textured ceramics with feeble magnetic susceptibility by colloidal processing in a high magnetic field.
\end{abstract}

[Received March 13, 2006]

Key-words : Colloidal processing, Nanostructured ceramics, Porous ceramics, Superplasticity, Textured ceramics, Zirconia, Alumina

\section{Introduction}

$\mathbf{F}_{\mathrm{a}}^{\mathrm{o}}$ OR the processing of ceramics by sintering, fine particles are desired not only to reduce the sintering temperature, but also to obtain fine-grained microstructures. However, fine particles will spontaneously agglomerate due to van der Waals forces to an extent that depends on their processing history. When agglomerated particles are used, wide variations in the pores size distributions are inevitably introduced into the green compact resulting in nonhomogeneous microstructures. Colloidal processing is a powerful method for consolidating fine particles with a high density and homogeneous microstructure. ${ }^{1)-3)}$ The key point is to use non-heavily agglomerated particles and stabilize each particle in a suspension. Usually the particles are dispersed by using an electrostatic repulsive force and/or steric stabilization. In two or more component systems, either a well-dispersed suspension or hetero-coagulated suspension is used. ${ }^{3), 4)}$ For the dispersed suspension of multi-component systems, segregation during colloidal filtration is a common problem due to differences in the sedimentation rate, but can be minimized using a suspension with a high solids content. ${ }^{3), 5)}$

I will first show superplastic zirconia polycrystals as a demonstration of the merit of colloidal processing using submicron sized commercial powders. I then introduce the fabrication of dense nano-sized zirconia by the following methods without pressure sintering; (1) direct pressure filtration of zirconia sols without the powdering step and low-temperature sintering, ${ }^{5)}$ (2) pressure filtration of $\mathrm{Cu}$ modified zirconia suspension and liquid-phase sintering ${ }^{6), 7)}$ (3) slip casting using nano-sized zirconia particles and their composites, and lowtemperature sintering. ${ }^{8)-10)}$ Next, I demonstrate the fabrication of porous ceramics with a controlled pore size by the hetero-coagulated suspension of ceramics and polymer. ${ }^{11)}$ In this case, the pore size and porosity could be easily tailored by varying the polymer size and the volume ratio of the polymer/ceramic particles. Finally, I show the colloidal processing, such as slip casting and electrophoretic deposition, under an external magnetic field to obtain the textured ceramics with a feeble magnetic susceptibility. ${ }^{12), 13)}$ The degree of orientation depends on the processing factors, such as heating temperature, particle size, applied magnetic field, concentration of the suspension, etc. This process technique confers several advantages and it is possible for this type of processing to be applied to many non-cubic ceramics.

2. Fine-grained superplastic zirconia polycrystals

Superplastic ceramics have been widely studied, since superplasticity was first reported in 1986 by Wakai et al. ${ }^{3), 14)}$ However, the application of the superplasticity to the precise deformation process is limited because superplastic ceramics are only formed at relatively low-strain rates around $10^{-4} \mathrm{~s}^{-1}$ and at higher temperatures above $1673 \mathrm{~K} .{ }^{14)}$ Recently, Hiraga et al. demonstrated that high-strain-rate (above $10^{-2} \mathrm{~s}^{-1}$ ) superplastic multi-phase ceramics in the systems of aluminaspinel-zirconia ${ }^{15)}$ and spinel-zirconia, ${ }^{16), 17)}$ where the highest strain rate at $0.1^{-1} \mathrm{~s}^{-1}$ have been established. ${ }^{15), 18)}$

In this session I will demonstrate the merit of the colloidal processing for fabricating high-strain-rate monolithic superplastic zirconias by adding dopants to $3 \mathrm{YTZ}\left(3 \mathrm{~mol} \% \mathrm{Y}_{2} \mathrm{O}_{3}\right.$ doped $\mathrm{ZrO}_{2}$ ). Here, doping is for enhancing the cation diffusion as described later, and colloidal processing is for preparing a fine-grained and homogeneous microstructure. ${ }^{3)}$

\section{$2.13 Y T Z$ polycristal}

A well-dispersed 3YTZ (Tosoh, average particle size $90 \mathrm{~nm}$ ) suspension was prepared by adding the appropriate amount of polyelectrolyte (ammonium polyacrylate; Toa gohsei, ALON A-6114) due to the electrosteric stabilization and by ultrasonic irradiation $(20 \mathrm{kHz}, 160 \mathrm{~kW}$ for $10 \mathrm{~min})$ for re-dispersion of the softly-agglomerated particles. ${ }^{19)}$ Here, it is noted that heavily-agglomerated particles cannot be re-dispersed by ultrasonic irradiation, ${ }^{20)}$ but recently it was confirmed that it can be re-dispersed by the beads milling technique using small 3 YTZ beads less than $50 \mu \mathrm{m}$ in diameter. ${ }^{21)}$ After evacuation in a desiccator to eliminate the air bubbles, the suspension was consolidated by slip casting. The obtained green compacts showed a narrow pore size distribution resulting in a low-tem- 


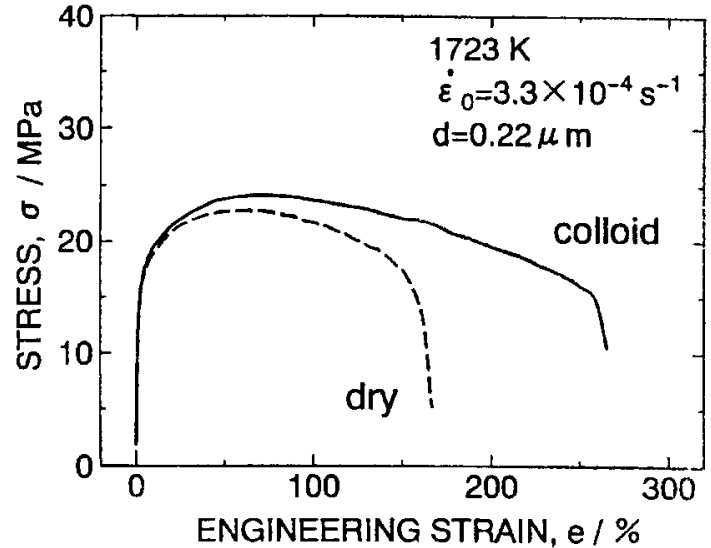

Fig. 1. Comparison of tensile elongation of $3 \mathrm{YTZ}$ prepared by slip casting (colloid) and conventional dry processing (dry).

perature sintering $(1573 \mathrm{~K})$ and high density (above 99\%) without large pores.

Figure 1 compares the tensile elongation of the $3 \mathrm{YTZ}$ polycrystal prepared by slip casting (colloidal) with the conventional dry processed polycrystal (dry), in which the grain sizes of both samples are controlled to the same size of 0.22 $\mu \mathrm{m} .{ }^{3), 22)}$ A quantitative analysis of the cavity numerical densities and growth rates reveals that the damage in $3 \mathrm{YTZ}$ is controlled by the cavity growth and that the total cavitated volume is a sum of the growth of the preexistent pores after sintering and the nucleation and growth of new cavities during the tensile test. ${ }^{3), 22)}$ The superiority of colloidal processing is due to reducing the initial large pores.

$2.2 \mathrm{Al}_{2} \mathrm{O}_{3}, \mathrm{Al}_{2} \mathrm{O}_{3}$ and $\mathrm{Mn}_{3} \mathrm{O}_{4}, \mathrm{MgO}$ and $\mathrm{TiO}_{2}$ added $3 \mathrm{YTZ}$ polycrystals

Dispersed aqueous suspensions of mixtures of $3 \mathrm{YTZ}, \mathrm{Al}_{2} \mathrm{O}_{3}$ and $\mathrm{Mn}_{3} \mathrm{O}_{4},{ }^{23), 24)}$ and of $3 \mathrm{YTZ}, \mathrm{MgO}$ and $\mathrm{TiO}_{2}{ }^{25), 26)}$ fine particles are prepared and consolidated by slip casting. Finegrained and dense sintered specimens are obtained by low temperature sintering of $1573 \mathrm{~K}$.

Figure 2 shows the effect of the $\mathrm{Al}_{2} \mathrm{O}_{3}$ addition on the tensile elongation and flow stress at $1573 \mathrm{~K} .{ }^{23)}$ Significant improvement in the tensile ductility was confirmed by the small amount of $\mathrm{Al}_{2} \mathrm{O}_{3}$ addition. To determine the high-deformation rate mechanism, the strain rate was analyzed by the following equation.

$$
\mathrm{d} \varepsilon / \mathrm{d} t=A \sigma^{n} / d^{\mathrm{p}} \exp (-Q / R T),
$$

where $A$ is a constant, $n$ is the stress exponent, $d$ is the initial grain size, $p$ is the grain size exponent, $Q$ is the deformation activation energy, $R$ is the gas constant, and $T$ is the absolute temperature. The $n$ value of the $0.3 \mathrm{vol} \% \mathrm{Al}_{2} \mathrm{O}_{3}$ dispersed 3 YTZ was evaluated as 2.2 at $1673 \mathrm{~K}$ and the $Q$ value was 519 $\mathrm{kJ} / \mathrm{mol}$. These values are consistent with previous data of $n=$ 2 and $Q=480 \mathrm{~kJ} / \mathrm{mol}$ for the conventional processed samples where the initial grain size was $0.4 \mu \mathrm{m} .{ }^{27)}$ The grain size refinement to $0.23 \mu \mathrm{m}$ did not affect the stress exponent and the activation energy. Three factors are considered to contribute to the enhancement of the tensile ductility; one is the enhanced cation diffusion, second is the refinement of the grain size, and third is a decrease in the initial defects and homogeneous distribution of $\mathrm{Al}_{2} \mathrm{O}_{3} .{ }^{28)}$

In all the systems, grain growth and creep, controlled by cation diffusion, ${ }^{29)}, 30$ ) were enhanced in comparison with 3YTZ. ${ }^{23)-28}$ In general, enhancement of the grain growth

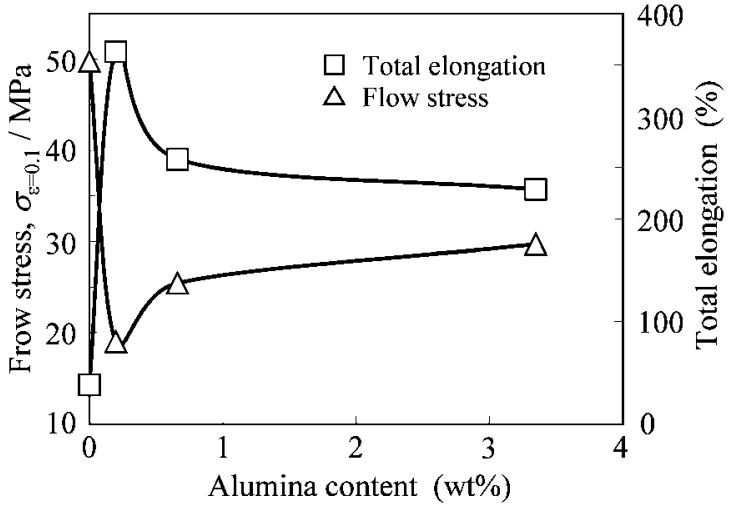

Fig. 2. Effect of alumina content of flow stress at a true stress of 0.1 and total tensile elongation at $1573 \mathrm{~K}$ at an initial strain rate of around $10^{-4} \mathrm{~s}^{-1}$.

results in an increased flow stress. This seems to be a disadvantage for the superplasticity, but the accommodation process is also enhanced due to the enhancement of the cation diffusion. Hence, the relationship between grain growth and the accomodation process are trade-offs. In this case (at high-strain rate and low-temperature), the second one is more effective.

Here, three types of high-strain-rate superplastic tetragonal zirconia were fabricated: (1) a small amount of alumina added $3 \mathrm{YTZ}^{23}$ (2) a small amount of manganese oxide and alumina added $3 \mathrm{YTZ},{ }^{24)}$ and (3) titania and magnesia added 3 YTZ. ${ }^{25)}$ Especially, the tensile ductility of about $310 \%$ was established in the third system at the low temperature of $1623 \mathrm{~K}$ and high-strain-rate of $\left.1.2 \times 10^{-2} \mathrm{~s}^{-1} .{ }^{25}\right)$

\section{Nanostructured zirconia-based ceramics}

3.1 Monoclinic zirconia without powdering step

A monoclinic zirconia sol was prepared by hydrolyzing the zirconium oxycloride octahydrate as follows. ${ }^{5)} \mathrm{ZrCl} 2 \mathrm{O} \cdot 8 \mathrm{H}_{2} \mathrm{O}$ $\rightarrow \mathrm{ZrO}_{2}+2 \mathrm{HCl}+7 \mathrm{H}_{2} \mathrm{O}$. Since zirconia particles show a large positive zeta potential in strong acids, the as-prepared zirconia nanoparticles are immediately dispersed into a strong hydrochloric acid solution which results in a well-dispersed aqueous zirconia suspension. The solid content of the sol was $2 \mathrm{vol} \%$ and the $\mathrm{pH}$ was 1.7. However, the zirconia sol inevitably involves chloride ions, considered to inhibit the sintering of zirconia. ${ }^{31)}$ To eliminate the chloride ions without changing the dispersion of the suspension, an ion exchange method was applied using an anion exchange resin..$^{5)}$ By this method, most of the chloride ions were removed in the acid state $(\mathrm{pH}=3.6)$, which indicates that the nanoparticles retain a high positive zeta-potential. The dechlorinated and concentrated (up to $10 \mathrm{vol} \%$ ) zirconia sol was consolidated by pressure filtaration at $10 \mathrm{MPa}$. The green density of the monoclinic zirconia after pressure filtration and CIP treatment was $49 \%$. The zirconia compact is densified by pressureless sintering to $98 \%$ of the theoretical density in air at $1100^{\circ} \mathrm{C}$ for $6 \mathrm{~h}$ (Fig. 3). The average grain size of the sintered monoclinic zirconia determined by the linear intercept method was $92 \mathrm{~nm}$. This simple and easy method is superior for the production of dense monoclinic zirconia nanoceramics.

3.2 Nanosized 3YTZ by liquid phase sintering

Tosoh's 3Y-TZ powder was dispersed with the aid of ultrasonic irradiation at $20 \mathrm{kHz}$ and $160 \mathrm{~W}^{19)}$ and magnetic stirring in the aqueous solution of ammonium hydroxide and ammonium nitrate thus keeping the total $\left[\mathrm{NH}^{3+} \mathrm{NH}^{4+}\right]$ equal to 


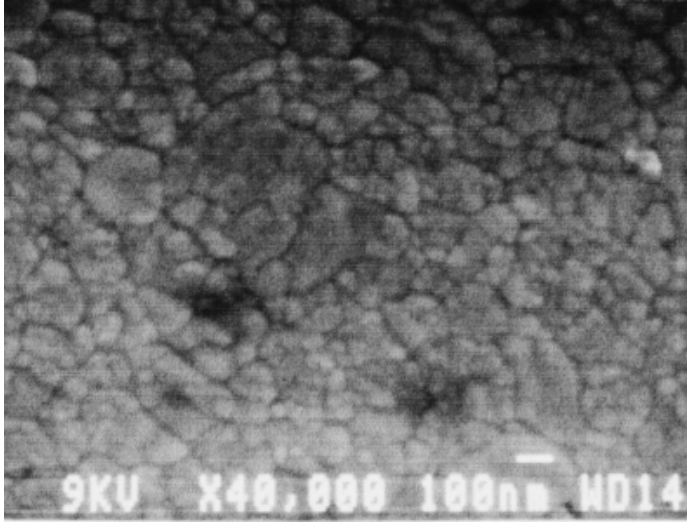

Fig. 3. SEM photo of monoclinic dense zirconia.

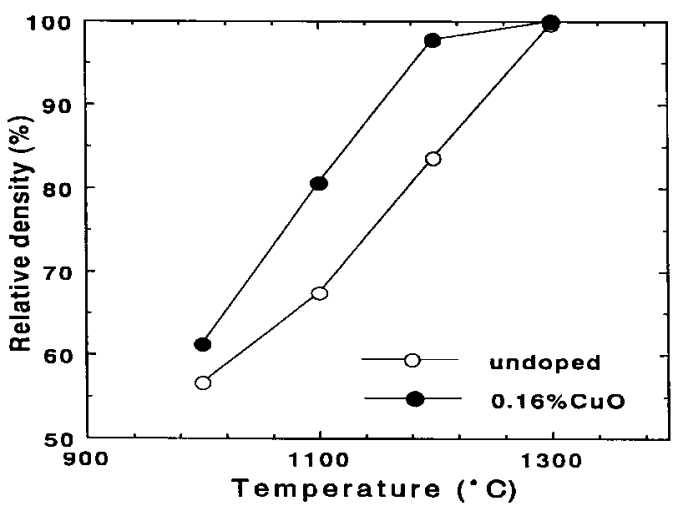

Fig. 4. Comparison of sintering behavior of undoped and $\mathrm{Cu}$-doped 3 YTZ.

$0.1 \mathrm{M}^{7}{ }^{7} \mathrm{Cu}^{2+}$ was added to the solutions by pipetting up to 10 $\mathrm{mL}$ of a $2.2 \times 10^{3} \mathrm{M}$ solution of $\mathrm{Cu}\left(\mathrm{NO}_{3}\right)_{2}$. Here, the $\mathrm{Cu}^{2+}$ adsorption on the $3 \mathrm{Y}-\mathrm{TZ}$ powder obeyed the Langmur type adsorption isotherm. The initial $\mathrm{pH}$ was adjusted to 11 . Since the zeta potential of the $3 \mathrm{YTZ}$ at $\mathrm{pH}=11$ was $-43.5 \mathrm{mV},{ }^{6}$ ) a well-dispersed suspension was obtained. ${ }^{7)}$ The green densities of $0.16 \mathrm{~mol} \% \mathrm{CuO}$-doped $3 \mathrm{Y}-\mathrm{TZ}$ after the $\mathrm{PF}$ at $10 \mathrm{MPa}$ and CIP treatment at $400 \mathrm{MPa}$ were $37.7 \%$ and $51.8 \%$ of the theoretical, respectively. CIP treatment is quite effective for increasing the density and decreasing the mean pore size that was determined by mercury porosimetry. $\mathrm{CuO}$ doping decreased the initial shrinkage temperature due to the liquid phase sintering as is shown in Fig. 4. The mean grain size of the $0.16 \mathrm{~mol} \% \mathrm{CuO}$-doped samples sintered at $1200^{\circ} \mathrm{C}$ was 84 nm. ${ }^{6}$ It is noted that a small amount of CuO-doped Y-TZ with a narrow pore size distributions densifies at lower temperatures resulting in a fine-grained polycrystal.

3.3 Nanostructure zirconia systems by nanoparticle synthesis and colloidal processing

The nano-size 3YTZ powder was prepared by hydrothermal coprecipitation from a sol of metal chlorides and urea followed by dispersion and calcination. ${ }^{8), 32)}$ A non-agglomerated 3 YTZ powder consisting of uniform nanosized aggregates (about $30 \mathrm{~nm}$ ) can be prepared using the optimum parameters of the synthesis conditions, powder treatment, controlled calcinations, etc. as seen in Fig. 5. Aqueous suspensions were prepared containing the synthesized 18 to $20 \mathrm{vol} \% 3 \mathrm{YTZ}$ nano-particles and 0.2 to $0.7 \mathrm{wt} \%$ alumina ( $\gamma$-alumina pow-

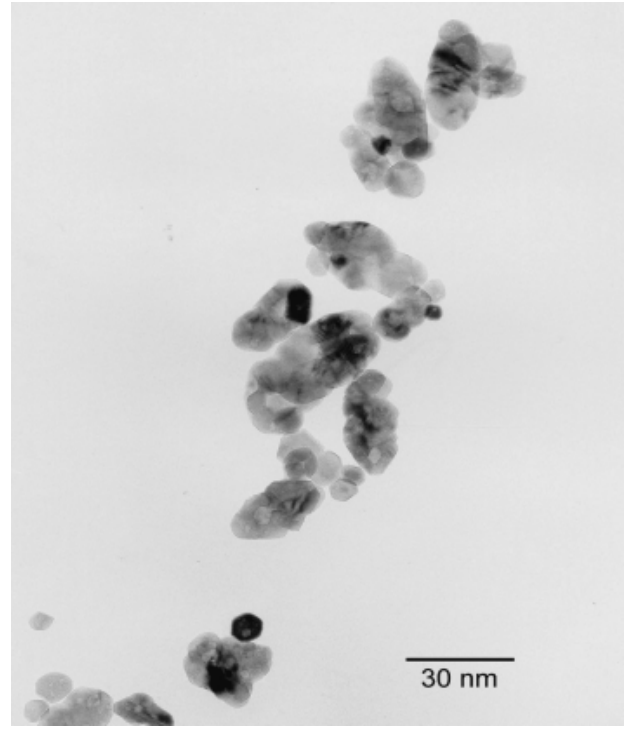

Fig. 5. 3YTZ aggregate prepared by using optimum conditions.

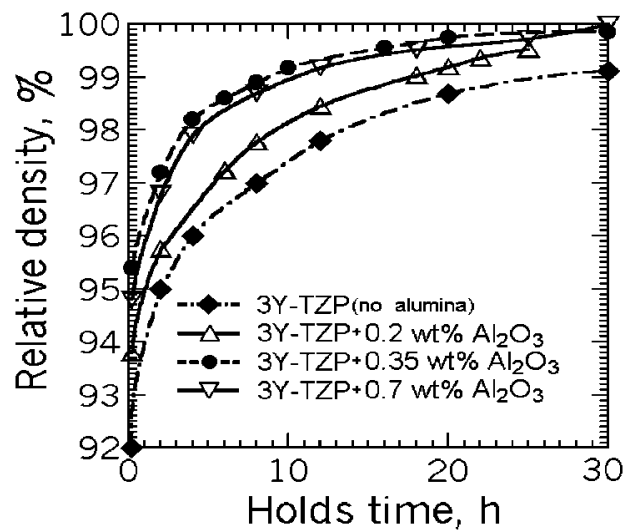

Fig. 6. Relative densities of $\mathrm{Al}_{2} \mathrm{O}_{3} / 3 \mathrm{Y}$-TZP intering at a constant temperature of $1150^{\circ} \mathrm{C}$.

der, NanoTek, particle size of $30 \mathrm{~nm}$ )-doped 3Y-TZP by adding the dispersant (ammonium polycarboxylate). Consolidations of the suspensions by slip casting and subsequent CIP at $400 \mathrm{MPa}$ were applied. The green bodies with a relative density of $42-44 \%$ were obtained by slip casting. The relatively high (for nano-powder) density of the $47-49 \%$ was achieved after CIPing.

By using the uniform nanosized-aggregates, the densification can be completed at a lower temperature. The sintering characteristics at $1150^{\circ} \mathrm{C}$ for the $3 \mathrm{YTZ}$ and alumina-doped 3YTZ samples are shown in Fig. 6. The addition of a small amount of alumina allowed the densification rate to be increased in comparison to the alumina-free 3 Y-TZP samples. ${ }^{10}$ Figure 7 (a) shows the SEM microstructure of the $0.35 \mathrm{wt} \%$ $\mathrm{Al}_{2} \mathrm{O}_{3} / 3 \mathrm{Y}$-TZP sintered at a temperature of $1150^{\circ} \mathrm{C}$ for $20 \mathrm{~h}$. The addition of the alumina enhanced the sintering process, shortened the sintering time and allowed the ceramic microstructure to remain ion a nano-order scale. The sintered bodies had varied densities (92 to $100 \%$ relative density) and grain sizes (60 to $160 \mathrm{~nm}$ ) depending of the sintering parameters and composition. ${ }^{33)}$

The possibility of engineering the $\mathrm{Pt} / 3 \mathrm{Y}$-TZP composite 

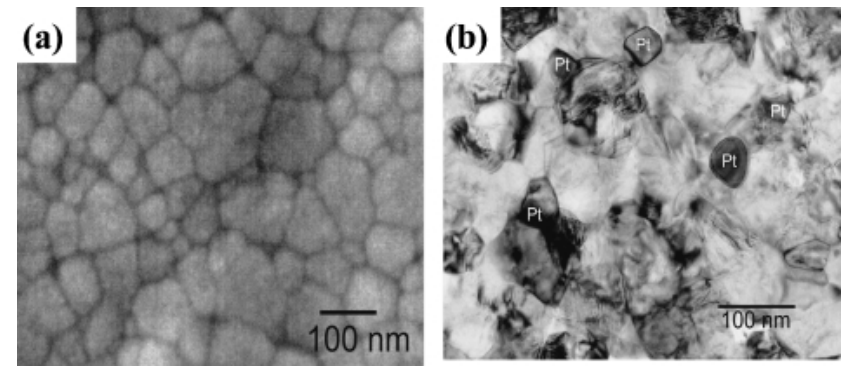

Fig. 7. SEM photograph of $0.35 \mathrm{wt} \% \mathrm{Al}_{2} \mathrm{O}_{3} / 3 \mathrm{Y}-\mathrm{TZP}$ ceramic sintered at $1150^{\circ} \mathrm{C}$ for $20 \mathrm{~h}$. (a), and TEM photograph of $1.5 \mathrm{wt} \% \mathrm{Pt} /$ $3 \mathrm{Y}$-TZP composite sintered at $1150^{\circ} \mathrm{C}$ for $30 \mathrm{~h}(\mathrm{~b})$.

nano-aggregates was also studied, where Pt metal ions were sonochemically reduced from aqueous solutions onto the surface of the $3 \mathrm{YTZ}{ }^{10)}$,34) Reagent-grade $\mathrm{K}_{2} \mathrm{PtCl}_{4}$ and sodium dodecyl sulfate (SDS) as a surfactant were used in this study. The aqueous suspension of the zirconia nano-aggregates was impregnated with an aqueous solution of $\mathrm{K}_{2} \mathrm{PtCl}_{4}$. A multiwave ultrasound generator (Model Kaijo 4021) with a $65 \mathrm{~mm}$ diameter barium titanate oscillator was operated at $200 \mathrm{kHz}$ with an input power of $200 \mathrm{~W}$. It was confirmed by TEM that the Pt nano-particles $(\sim 2 \mathrm{~nm})$ produced by the sonochemical reduction were impregnated into the $3 \mathrm{YTZ}$ nano-aggregates (20-45 nm). An aqueous suspension of the Pt/3Y-TZP composite nano-aggregates was prepared using a method similar of that of $3 \mathrm{Y}-\mathrm{TZP}$. After slip casting and CIP treatment, the sample was sintered at $1150^{\circ} \mathrm{C}$ in air. A dense of Pt-zirconia nanocomposite was fabricated as shown in Fig. 7(b).

\section{Porous ceramics}

Porous materials are of significant interest due to their wide applications, and various processing techniques have been employed to tailor different porous structures in the ceramic materials. The use of pore formers or foaming agents that evolve gases during calcination is a common method. ${ }^{35)-37)}$ Partial sintering has also been used as an alternative approach to obtaining porous structures. $\left.{ }^{38)}-40\right)$ However, these processes generally produce macroporous structures with a wide pore sizes distribution.

Recently, we have proposed a novel approach to prepare porous materials with a controlled pore size and porosity via a hetero-coagulation method (Fig. 8). ${ }^{11)}$ Our strategy is based on the templating-assisted approach of a core-shell composite. Monodispersed polymer spheres are used as templates and the ceramic particles act as the target materials. By particle surface modification, well-dispersed suspensions of the polymer and ceramic particles with high opposite charges could be obtained under the same $\mathrm{pH}$ condition, which is very important for preparing uniform core-shell composites. Upon mixing the two suspensions, core-shell structures are formed via electrostatic attraction. The flocculated particles are subsequently closely packed by vacuum filtration. The polymers are finally removed by calcination, resulting in the porous structures.

Figure 9 shows the zeta potential $(\xi)$ of $\alpha-\mathrm{Al}_{2} \mathrm{O}_{3}$ (average particle size $200 \mathrm{~nm}$ ) and the polymer (polymethyl methacrylate, P800: average particle size $800 \mathrm{~nm}$ ) versus $\mathrm{pH} .{ }^{41)}$ The polymer is negatively charged in the measured $\mathrm{pH}$ range of 3-12. A relatively high $\xi$ value can be obtained between $\mathrm{pH} 6$ and 10 , indicating that the polymer suspension is welldispersed in this $\mathrm{pH}$ range. On the other hand, the $\alpha-\mathrm{Al}_{2} \mathrm{O}_{3}$
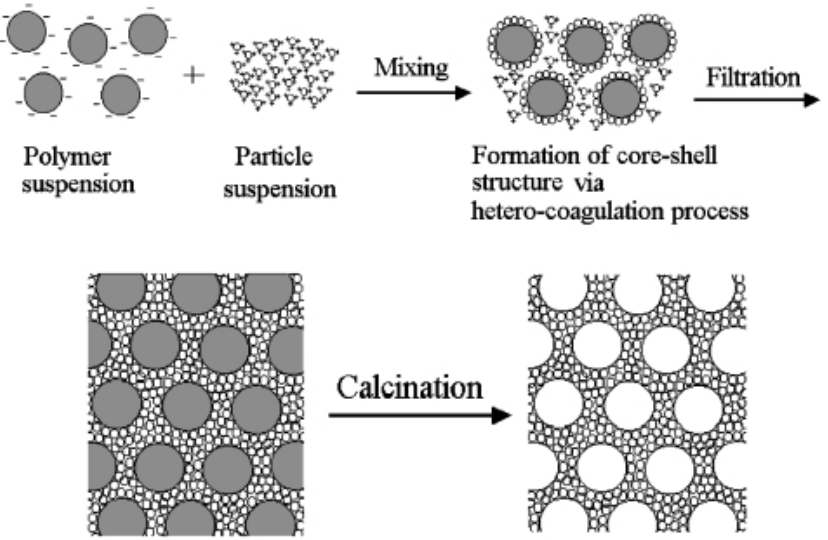

Inorganic-organic composite

Porous materials

Fig. 8. Schematic procedure for fabrication of macroporous materials via core-shell flocculation of polymer spheres and inorganic particles.

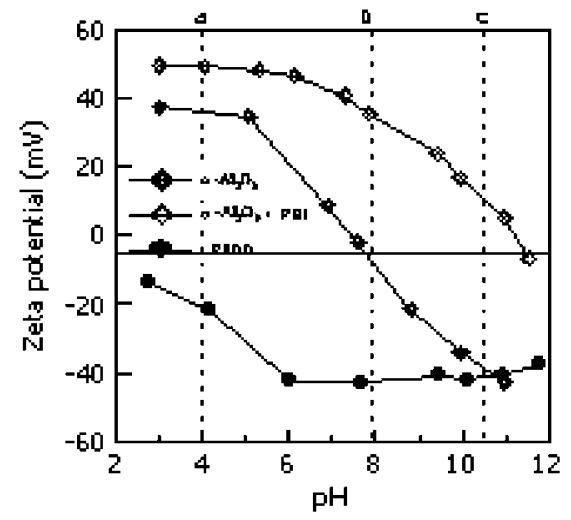

Fig. 9. Zeta potentials of polymer (P800) and $\alpha-\mathrm{Al}_{2} \mathrm{O}_{3}$ in the presence/absence of PEI in aqueous suspensions.

with a highly positive surface charge $(\xi \geq 30 \mathrm{mV})$ can be obtained only below pH 5. For the purpose of preparing two well-dispersed suspensions under the same $\mathrm{pH}$, PEI was used as the cationic dispersant to modify and enhance the positive charge potential of the $\alpha-\mathrm{Al}_{2} \mathrm{O}_{3}$ surfaces. The isoelectric point (iep) of $\alpha-\mathrm{Al}_{2} \mathrm{O}_{3}$ shifted from $\mathrm{pH} 7.5$ to $\mathrm{pH} 11$ with the PEI addition, and a highly positive $\xi$ value of over $30 \mathrm{mV}$ in the $\mathrm{pH}$ range of 3-8.5 can be obtained. Taking into account the $\xi$-potential results of both the polymer and alumina powder, pH 8 was chosen to prepare the $\alpha-\mathrm{Al}_{2} \mathrm{O}_{3}$ and the polymer suspensions.

Figure 10 shows the SEM images of the porous $\alpha-\mathrm{Al}_{2} \mathrm{O}_{3}$ prepared using the polymethyl metacrylate particle (Soken Chem. Co., P800) template. The pores are uniformly distributed throughout the entire sample, and 3-dimensional porous structures can be seen through the pore windows of the next layer. The wall thickness, density and porosity of the materials depend on the volume ratio of the ceramic/polymer particles. Porous alumina with a $75.5 \%$ porosity could be obtained when the volume ratio of $\mathrm{Al}_{2} \mathrm{O}_{3} / \mathrm{P} 800$ was 0.42 , which is very close to the ideal voids of close packed spheres, strongly suggesting the well-defined pore structure and uniform pore distribution in this material.

Similar macoporous ceramic materials prepared with different polymer template sizes via a similar synthetic procedure 


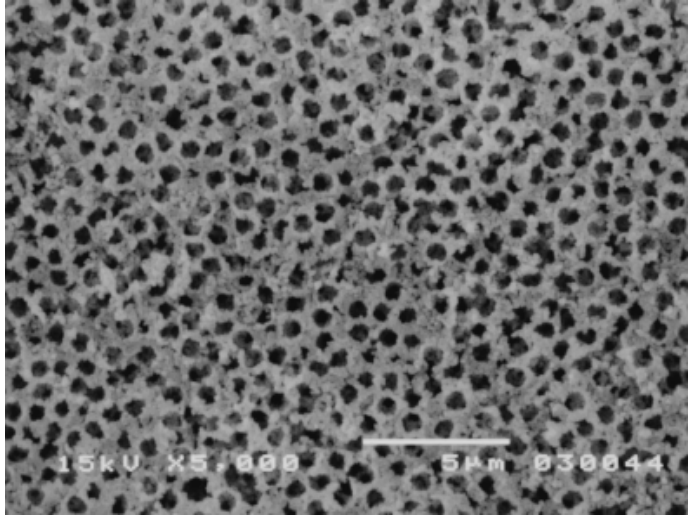

Fig. 10. SEM photograph of porous $\alpha-\mathrm{Al}_{2} \mathrm{O}_{3}$.

such as porous $\gamma-\mathrm{Al}_{2} \mathrm{O}_{3}, \mathrm{TiO}_{2}, \mathrm{ZrO}_{2}$, etc. ${ }^{42)-44)}$

\section{Textured ceramics}

The controlled development of texture is one of the ways for effectively improving various properties. ${ }^{45)}$ Textured ceramics have been produced by a variety of techniques; such as tape casting, hot forging and templated or seeded grain growth. ${ }^{45)}$ Recently, we have demonstrated that the crystal orientation of feeble magnetic materials such as alumina can be controlled by colloidal processing in a high magnetic field. ${ }^{12), 44)}$

The principle of the process is that a crystal with an anisotropic magnetic susceptibility will rotate to an angle minimizing the system energy when placed in a magnetic field. The magnetic torque $T$ attributed to the interaction between the anisotropic susceptibility and a magnetic field can be estimated by Eq. (2).

$$
T=-\Delta X \mathrm{VB}^{2} \sin 2 \theta / 2 \mu_{0}
$$

where $\Delta X,\left(=1 X_{\mathrm{a}, \mathrm{b}}-X_{\mathrm{c}} \mathrm{l}\right)$ is the anisotropy of the magnetic susceptibilities which are measured for the $a, b$-axis $\left(X_{a, b}\right)$ and $c$-axis $\left(X_{\mathrm{c}}\right), V$ is the volume of the materials, $B$ is the applied magnetic field, $\theta$ is the angle between an easy magnetization axis in a crystal and imposed magnetic field direction, and $\mu_{0}$ is the permeability in a vacuum. This magnetic torque is the driving force for the magnetic alignment.

To obtain the oriented materials with feeble magnetic susceptibilities, the following conditions are necessary: ${ }^{12)}$ 1) the crystal structure is non-cubic in order to apply the anisotropic magnetic susceptibilities, 2) the particle is a single crystal and well dispersed, 3 ) the viscosity of the suspension is low enough to rotate the particles with a low energy, and 4) grain growth is necessary to obtain a highly oriented structure especially when a spherical particle is used. We have fabricated many kinds of oriented ceramics by slip casting in a high magnetic field followed by sintering, such as $\mathrm{Al}_{2} \mathrm{O}_{3}, \mathrm{TiO}_{2}, \mathrm{ZnO}, \mathrm{AlN}$, $\mathrm{SiC}$, etc. ${ }^{12), 46)-51)}$ their composites, ${ }^{52), 53)}$ and multi-component ceramics of $\beta-\mathrm{Al}_{2} \mathrm{O}_{3}{ }^{54)}$ and $\mathrm{Al}_{2} \mathrm{O}_{3}$-SiC-mullite nanocomposite ${ }^{55), 56)}$ by reaction sintering. However, when we use whisker or plate-like particles, special attention is necessary due to the effect of gravity energy ${ }^{57), 58)}$ that is the highest energy in the colloidal dispersion system. ${ }^{59)}$ The effect also strongly depends on the easy magnetization angle, which has been described elsewhere. ${ }^{58)}$

Uchikoshi et al. demonstrated that EPD in a high magnetic field is an excellent method to fabricate crystalline textured ceramic thick bodies. ${ }^{59)-62)}$ Here, the direction of the electric field relative to the magnetic field can be altered to control the

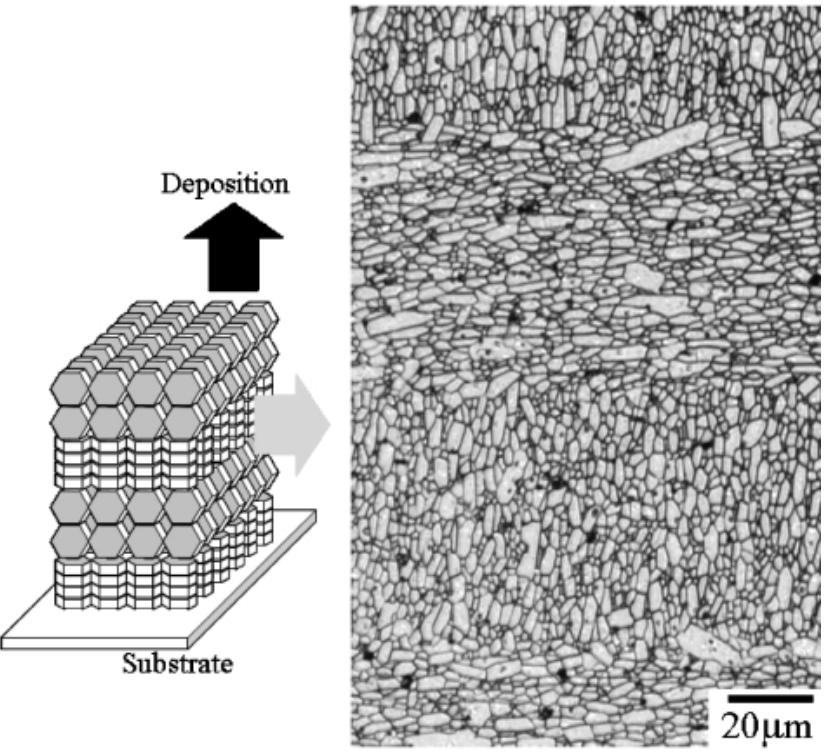

Fig. 11. Schematic illustration and the cross-sectional microstructure of a crystalline-textured alumina/alumina laminated composite prepared by electrophoretic deposition in strong magnetic field (12 $\mathrm{T})$, where the direction of the electric current relative to the magnetic field is alternately changed to $0^{\circ} / 90^{\circ}$, layer by layer.

dominant crystal faces. Figure 11 shows a crystalline-textured alumina/alumina laminated composite, where the angle is alternately changed to $0^{\circ} / 90^{\circ}$, layer by layer. This method can also be applied to prepare crystalline-oriented or specific crystal face thin films for functional applications. ${ }^{63), 64)}$

Acknowledgments I wish to thank Dr. K. Hiraga, Dr. T. Uchikoshi, Dr. T. S. Suzuki, Dr. F.Q. Tang and Dr. O. Vasylkiv for their great contributions of this work. I also wish to express my sincere thanks to all of the researchers, engineers and students of collaborative work for their efforts to achieve the research. This work was supported by the Budget for Nuclear Research and the Grant-in-Aid for Scientific Research from the Ministry of Education, Culture, Sports, Science and Technology.

\section{References}

1) Lange, F. F., J. Am. Ceram. Soc., Vol. 72, pp. 3-14 (1989).

2) Aksay, I. A., Ceramics Inter., Vol. 17, pp. 267-274 (1991).

3) Sakka, Y. and Hiraga, K, Nippon Kagaku Kaishi, pp. 497-508 (1999).

4) Uchikoshi, T., Sakka, Y. and Hiraga, K., J. Electroceram., Vol. 4, pp. 113-120 (1999).

5) Hirata, Y., Haraguchi, I. and Ichihara, Y., J. Mater. Res., Vol. 7, pp. 2572-2578 (1992).

6) Sakka, Y., Ozawa, K., Uchikoshi, T. and Hiraga, K., J. Am. Ceram. Soc., Vol. 84, pp. 2129-2131 (2001).

7) Sakka, Y., Suzuki, T. S., Ozawa, K., Uchikoshi, T. and Hiraga, K, J. Ceram. Soc. Japan, Vol. 109, pp. 1004-1009 (2001).

8) Vasylkiv, O. and Sakka, Y., J. Am. Ceram. Soc., Vol. 84, pp. 2489-2494 (2001).

9) Vasylkiv, O., Sakka, Y. and Skorokhod, V. V., J. Am. Ceram. Soc., Vol. 86, pp. 299-304 (2003).

10) Vasylkiv, O., Sakka,Y., Maeda, Y. and Skorokhod, V. V., J. Am. Ceram. Soc., Vol. 88, pp. 639-644 (2005).

11) Tang, F. Q., Fudouzi, H., Uchikoshi, T. and Sakka, Y., J. Eur. Ceram. Soc., Vol. 24, pp. 341-347 (2004).

12) Sakka,Y. and Suzuki, T. S., J. Ceram. Soc. Japan, Vol. 113, pp. 26-36 (2005)

13) Uchikoshi, T., Suzuki, T. S., Okuyama, H. and Sakka, Y., J. Mater. Res., Vol. 19, pp. 1487-1491 (2004). 
14) Wakai, F., Sakaguchi, S. and Matsuno, Y., Adv. Ceram. Mater., Vol. 1, pp. 259-263 (1986).

15) Kim, B.-N., Hiraga, K., Morita, K. and Sakka, Y., Nature, Vol. 413, pp. 288-291 (2001).

16) Morita, K., Hiraga, K. and Sakka, Y., J. Am. Ceram. Soc., Vol. 85, pp. 1900-1902 (2002).

17) Morita, K., Hiraga, K., Kim, B.-N. and Sakka, Y., Mater. Trans., Vol. 45, pp. 2073-2077 (2004).

18) Hiraga, K., Kim, B.-N., Morita, K., Suzuki, T. S. and Sakka, Y., J. Ceram. Soc. Japan, Vol. 113, pp. 191-197 (2005)

19) Suzuki, T. S., Sakka, Y., Nakano, K. and Hiraga, K., J. Am. Ceram. Soc., Vol. 84, pp. 2132-2134 (2001).

20) Suzuki, T. S., Sakka, Y., Nakano, K. and Hiraga, K., J. Ceram. Soc. Japan, Vol. 110, pp. 927-930 (2002).

21) Inkyo, M. and Tahara, T., J. Soc. Powder Powder Technol. Japan, Vol. 41, pp. 578-585 (2004) [in Japanese].

22) Hiraga, K. and Nakano, K., Mater. Sci. Forum, Vol. 243, pp. 387-392 (1997).

23) Suzuki, T. S., Sakka, Y., Morita, K. and Hiraga, K., Scripta Mater., Vol. 43, pp. 705-710 (2000).

24) Sakka, Y., Ishii, T., Suzuki, T. S., Morita, K. and Hiraga, K., J. Eur. Ceram. Soc., Vol. 24, pp. 449-453 (2004).

25) Sakka, Y., Matsumoto, T., Suzuki, T. S., Morita, K., Kim, B.-N., Hiraga, K. and Moriyoshi, Y., Adv. Eng. Mater., Vol. 5, pp. 130-133 (2003).

26) Sakka, Y., Suzuki, T. S., Matsumoto, T., Morita, K., Hiraga, K. and Moriyoshi, Y., Solid State Ionics, Vol. 174, pp. 499-503 (2005).

27) Sato, E., Morioka, H., Kuribayashi, K. and Sundararaman, D., J. Mater. Sci., Vol. 34, pp. 4511-4518 (1999).

28) Sakka, Y., Suzuki, T. S., Morita, K., Nakano, K. and Hiraga, K., Scripta Mater., Vol. 44, pp. 2075-2078 (2001).

29) Sakka, Y., Oishi, Y. and Ando, K., J. Mater. Sci., Vol. 17, pp. 3101-3105 (1982).

30) Sakka, Y., Oishi, Y., Ando, K. and Morita, S., J. Am. Ceram. Soc., Vol. 74, pp. 2610-2614 (1991).

31) Readey, M. J. and Readey, D. W., J. Am. Ceram. Soc., Vol. 69, pp. 580-580 (1986).

32) Vasylkiv, O. and Sakka, Y., J. Ceram. Soc. Japan, Vol. 109, pp. 500-505 (2001).

33) Vasylkiv, O., Sakka, Y. and Skorokhod, V. V., Mater. Trans., Vol. 44, pp. 2235-2238 (2003).

34) Vasylkiv, O., Sakka, Y., Maeda, Y. and Skorokhod, V. V., J. Eur. Ceram. Soc., Vol. 24, pp. 469-473 (2004).

35) Corbin, S. F. and Apte, P. S., J. Am. Ceram. Soc., Vol. 82, pp. 693-701 (1999).

36) Sodeyama, K., Sakka, Y., Kamino, Y. and Tabata, I., J. Ceram. Soc. Japan, Vol. 104, pp. 963-968 (1996).

37) Sodeyama, K., Sakka, Y., Kamino, Y., Hamaishi, K., Kokusho, T. and Seki, H., J. Ceram. Soc. Japan, Vol. 106, pp. 333-338 (1998).

38) Yang, J. F., Zhang, G. J. and Ohji, T., J. Mater. Res., Vol. 16, pp. 1916-1918 (2001).

39) Deng, Z. Y., Liu, Y. F., Tanaka, Y., Ye, J. H. and Sakka, Y., J. Am. Ceram. Soc., Vol. 88, pp. 977-979 (2005).
40) Deng, Z. Y., Tanaka, Y., Sakka, Y. and Kagawa, Y., J. Mater. Res., Vol. 20, pp. 672-679 (2005).

41) Tang, F. Q., Fudouzi, H. and Sakka, Y., J. Am. Ceram. Soc., Vol. 86, pp. 2050-2054 (2003).

42) Tang, F. Q., Fudouzi, H., Uchikoshi, T., Awane, T. and Sakka, Y., Chem. Lett., Vol. 32, pp. 276-277 (2003).

43) Tang, F. Q., Fudouzi, H., Zhang, J. and Sakka, Y., Scripta Mater., Vol. 49, pp. 735-740 (2003).

44) Sakka, Y., Tang, F. Q., Fudouzi, H. and Uchikoshi, T., Sci. Technol. Adv. Mater., Vol. 6, pp. 915-920 (2005).

45) Messing, G. L., Trolier-McKinstry, S., Sabolsky, E. M., Duran, C., Kwon, S., Brahmaroutu, B., Park, P., Yilmaz, H., Rehrig, P. W., Eitel, K. B., Suvaci, E., Seabaugh, M. and Oh, K. S., Critical Rev. Solid State Mater. Sci., Vol. 29, pp. 45-96 (2004).

46) Suzuki, T. S., Sakka, Y. and Kitazawa, K., Adv. Eng. Mater., Vol. 3, pp. 490-492 (2001).

47) Suzuki, T. S. and Sakka, Y., Chem. Lett., pp. 1204-1205 (2002).

48) Suzuki, T. S. and Sakka, Y., Jpn. J. Appl. Phys., Vol. 41, pp. 1272-1274 (2002).

49) Guilmeau, E., Chateigner, D., Suzuki, T. S., Sakka, Y., Henrist, C. and Ouladdiaf, B., Chem. Mater., Vol. 17, pp. 102-106 (2005).

50) Inoue, K., Sassa, K., Yokogawa, Y., Sakka, Y., Okida, M. and Asai, S., Trans. Mater., Vol. 44, pp. 1133-1137 (2003).

51) Suzuki, T. S. and Sakka, Y., Scripta Mater., Vol. 52, pp. 583-586 (2005).

52) Suzuki, T. S., Sakka, Y. and Kitazawa, K., J. Ceram. Soc. Japan, Vol. 109, pp. 886-890 (2001).

53) Suzuki, T. S. Uchikoshi, T. and Sakka, Y., J. Ceram. Soc. Japan, Vol. 114, pp. 59-62 (2006).

54) Sakka, Y., Honda, A., Suzuki, T. S. and Moriyoshi, Y., Solid State Inonics, Vol. 172, pp. 341-344 (2004).

55) Sakka, Y., Bidinger, D. D. and Aksay, I. A., J. Am. Ceram. Soc., Vol. 78, pp. 479-486 (1995).

56) Saito, S., Sakka, Y., Suzuki, T. S. and Nakata, T., Key Eng. Mater. (in press).

57) Sakka, Y., Suzuki, T. S., Tanabe, N., Asai, S. and Kitazawa, K., Jpn. J. Appl. Phys., Vol. 41, pp. 1416-1418 (2002).

58) Wu, C. Y., Li, S. Q., Sassa, K., Sakka, Y., Suzuki, T. S. and Asai, S., ISIJ Inter., Vol. 45, pp, 997-1000 (2005).

59) Hirata, Y., Nakagama, S. and Ishihara, Y., J. Mater. Res., Vol. 5, pp. 640-646 (1990)

60) Uchikoshi, T., Suzuki, T. S., Okuyama, H. and Sakka, Y., J. Mater. Res., Vol. 18, pp. 254-256 (2003).

61) Uchikoshi, T., Suzuki, T. S., Okuyama, H. and Sakka, Y., Ceramic Inter., Vol. 30, pp 1975-1978 (2004).

62) Suzuki, T. S., Uchikoshi, T., Okuyama, H. and Sakka, Y., J. Eur. Ceram. Soc., Vol. 26, pp. 661-665 (2006).

63) Doungdaw, S., Uchikoshi, T., Noguchi, Y., Eamchotchawalit, C. and Sakka, Y., Sci. Technol. Adv. Mater., Vol. 6, pp. 927-932 (2005).

64) Kumagai, T., Horii, S., Uchikoshi, T., Suzuki, T. S., Sakka, Y., Okamoto, T., Shimoyama, J. and Kishio, J., Jpn. J. Appl. Phys., Part 2, Vol. 44, pp. L1263-L1266 (2005).

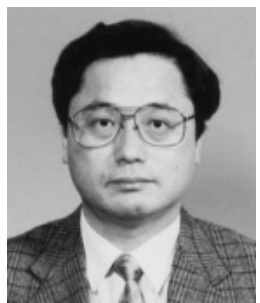

Yoshio Sakka is a director of fine ceramic processing group at National Institute for Materials Science (NIMS). He received his B.E. in 1978, M.E in 1980, and Ph. D. in 1983 from Kyushu University for his work on cationic diffusion of zirconia solid solution systems. After receiving his Ph.D, he joined National Research Institute for Metals (present NIMS). During 1991-92, he stayed a year in University of Washington (Prof. I. A. Aksay's Lab.). His current interests are focused on the diffusion-controlled phenomena and fine-particle processing. $\mathrm{He}$ is author or coauthors of 10 books and above 300 papers. 